\title{
Weather dependent effects of nest ectoparasites on their bird hosts
}

\author{
Santiago Merino and Jaime Potti
}

\begin{abstract}
Merino. S and Pottı. J 1996 Weather dependent effects of nest ectoparasites on their bird hosts - Ecography $19 \quad 107-113$

This study reports the relationships between ranfall and ambient temperature with the abundances and prevalences of three species of ectoparasitic arthropods (viz, mites. blowfly larvae. fleds) in pied flycatcher Ficedula hipoleuca nests in three different breeding seasons In addition to its effects on the growth of nestling pied flycatchers, weather conditions were found to determine patterns of abundance and prevalence of ectoparasites Nest ectoparasites had detrimental effects on the fitness (nestling growth and survival unul fledging) of their hosts although the effects and the identity of harmful ectoparasites varied across the years Among the three species of nest ectoparasites. mites had the most consistent harmful effects on nestling growth Fleas were detrimental in the more cold and rany year, while blowflies caused nestling mortality in the warmer year Different host-parasite interactions were present each year, most likely due to the effects of weather on the activity and timing of development of parasite populations
\end{abstract}

$S$ Mermo and J Pottı, Dept de Biologia Antmal Lnu Alcala de Henares E-2887I Alcala de Henares (Madrid). Spain

Parasitism is an important environmental component of the life cycle of most organısms (Price 1980), including birds (Møller et al 1990. Loye and Zuk 1991. Møller 1994a) The array of parasites a particular host sustains. each of them with widely differing modes of dispersal, host infection and reproductive rates, means that highly variable effects on hosts can be expected These effects can be either neutral (Rogers et al 1991), beneficial (Munger and Holmes 1988) or, more commonly, detr1mental (for reviews see Møller et al 1990, Lehman 1993) Some parasites, e g some nest ectoparasites, differ from other parasites in that they are only confronted by the hosts while breeding and their effects are not suffered by the adult hosts outside that part of the yearly cycle, instead, these nest ectoparasites drain resources mostly directly from the offspring, having their larger detrimental effects on growth and survival early in life (e g Moller 1990, Richner et al 1993, Merino and Pottı 1995) Some nest ectoparasites also live more or less permanently on the hosts (e g Møller 1994b), potentrally affectıng them throughout their entire lifetime
Some studies of birds and their nest parasites have shown that the detrimental effects of parasites are accentuated when environmental conditions for their hosts deteriorate, e $\mathrm{g}$ in situations of food scarcity or late breeding (Møller 1990, de Lope et al 1993. Merıno and Pottı 1995) However, almost all studies dealing with birds and nest ectoparasites have viewed the system from the host's point of view, implicitly assuming that the host environment somewhat buffers parasites from the effects of env1ronmental conditions While this may hold true for endoparasites (which. however, are exposed to 'environmental stress' in the form of host's immune response). this is not certainly the case for ectoparasites, as colonization of hosts by the parasites themselves is known to strongly depend on environmental conditions, host aggregation being one of the most obvious (Poulın 1991) Chmate variation is another potential powerful environmental effect to be faced by parasites, especially in the dispersal/colonization stages of finding suitable hosts (Marshall 1981)

Weather conditions are also an important factor affecting the growth and survival of young in popula-

Accepted 31 August 1995

Copynght (C) ECOGRAPHY 1996

ISSN 0906-7590

Printed in Ireland - all nghts reserved 
tions of insectivorous birds (e g Bryant 1975 , Jarvinen and Vaisanen 1984, Shields and Crook 1987. Elkıns 1988, Sasvárı and Hegyı 1993) As pointed out by Johnson and Albrecht (1993) the young of aerial and tree-gleaning insectivorous birds may be especrally vulnerable to the combined effects of spells of bad weather, which cause impaired food collection by parents and/or food shortages. and nest ectoparasites Thus, at least among these birds. the impact of ectoparasites may depend on the influence of weather conditions on host performance (de Lope et al 1993. Johnson and Albrecht 1993) However, both the activity of ectoparasites and the numerical development of their populations may be more influenced by weather (Marshall 1981) than the birds are The study of interactions between bird hosts and parasites should therefore consider the joint effects of weather on the brology and performance of both components of the system

We address in this paper the following two questions 1) do nest ectoparasite abundance or prevalence actually vary with prevalling weather conditions? 2 ) Has this variation any bearing on the effects of nest ectoparasites on their bird hosts? We illustrate these problems using the system formed by a passerine host, the pied flycatcher Ficedula hypoleuca and three arthropods infesting their nests, in a three-year study period with contrasting weather conditions

\section{Methods}

Nest ectoparasite populations and pred flycdtchers were studied from 1991 to 1993, in an old deciduous odk Quercus pyrenaica forest in central Spain (see Carrascal et al 1987 for description of the study area) All pied flycatcher pairs bred in nestboxes provided by us. thus allowing an easy control of nestling growth and estımates of nest ectoparasite populations Nearly all adult breeding birds were captured, weighed (to the nearest $01 \mathrm{~g}$ ) and measured for tarsus length (distance between bending points, to the nearest $005 \mathrm{~mm}$ ), and all nestlings were equally measured at the age of 13 days, when tarsus length has already attained the definitive, adult size (Pottı and Merino 1994) We also estimated the abundance of mites in the nest on the basis of a low vs high scoring system when the nestlings were measured (Merino and Pott1 1995) Nestlıng mortality was controlled from hatching to fledging Usually on the same or the following day that the young fledged, all nest contents were collected in labeled plastic bags, transported to the laboratory, and placed in Berlese funnels for $48 \mathrm{~h}$ The nest material was subsequently dismantled looking for other ectoparasites As counts of mites in Berlese funnels in 1991 were highly and positively re- lated to the sconng index of mite abundance used in day 13 of nestling life (Merino and Pott1 1995), this index of mite abundance was used when lookıng for effects on nestling development and survival We consider that a nest was infected by fleas when adults or larvae were present. but we did not try to quantıfy their numbers because counts in Berlese funnels do not adequately estımate fled abundance (see Harper et al (1992) for more adequate flea counting methods) Blowfly numbers were estımated by counting all puparia present among the nest material, and the abundance was categonzed by dividing nests in two classes, namely low (below the median) and high dbundances (Menno and Pottl 1995) Therefore. throughout this paper we will use dichotomous estrmates of abundance (low vs high) of mites and blowfly larvae. while prevalences (percentages of nests infested) are used for fleas only

To investigate the variation of parasite infestations across years and the possibility of interactions among parasite species, we conducted log-linear analysis (Sokal and Rohlf 1981) This procedure is in analogy with an analysis of variance in that total variance of frequency data is partitioned into different factors, making the testing of interactions between them possible We ran the test hierarchically, beginning with the highest order (4) interaction and proceeding backwards untıl all terms.interactions retained by the model reached significance $(p<005)$, so that dropping any of them would result in a significant lack of fit of the model

Da1ly rainfall and ambient temperatures were obtained from records of the meteorological station of Madriguera a nearby locality (distance $29 \mathrm{~km}$ ) which vegetation composition and altitude are similar to those of our study area In our study plots, both the nest ectoparasite populations grow, and the pied flycatcher nestlings hatch, in June (Pottl et al 1987. Merino and Pottı 1995), hence our weather analyses were restricted to this month It is worthy to note that, apart from weather, conditions were similar for both the flycatchers and their ectoparasites throughout all of the study period, as the nestboxes were cleaned in all years before the breeding season (Merino and Pottı 1995)

Throughout this paper, the date of laying of the first egg in the nests of pied flycatchers is used as an index of breeding phenology All statistical tests (Sokal and Rohlf 1981) are two-taled Non-parametric statistics were used when the premises for parametric tests were not fulfilled (e g number of dead nestlings) Sample sizes (Table 1) differ due to some accidents with collection bottles breaking or lacking alcohol and missing data in a few cases (e $g$ scoring of mite abundance was not attempted in some nests due to chillng weather in 1992) 
Table 1 Summary of the effects of three nest ectopdrasites on nestling growth (mean withın-brood measurements) and survival to fledgling in three yedrs Differences were tested with andlyses of variance, after controlling for significant variation due to genetic and environmental factors (see statistics in the Appendix), 0 no significant effect, - reduced growth in infested nests, + increased mortality in infested nests, $n$ sample size (number of nests) ${ }^{*}=p<005^{* *}=p<001$

\begin{tabular}{|c|c|c|c|c|c|c|c|c|c|}
\hline & \multicolumn{3}{|c|}{1991} & \multicolumn{3}{|c|}{1992} & \multicolumn{3}{|c|}{1993} \\
\hline & Mites & Blowfies & Fleas & Mites & Blowflies & Fleas & Mites & Blowfles & Fleas \\
\hline Tarsus & $-^{*}$ & 0 & 0 & 0 & 0 & $-^{*}$ & 0 & 0 & 0 \\
\hline Mass & $-* *$ & 0 & 0 & 0 & 0 & 0 & - * & 0 & 0 \\
\hline Dead nestings & 0 & $t^{*}$ & 0 & 0 & 0 & $t^{* *}$ & 0 & 0 & 0 \\
\hline $\mathrm{n}$ & 62 & 68 & 66 & 56 & 74 & 73 & 71 & 74 & 67 \\
\hline
\end{tabular}

\section{Results}

\section{Nest ectoparasites}

Three species of parasitic arthropods were found from the nests the mite Dermanysus gallinotdes Moss 1966 the flea Ceratophyllus gallinae Schrank 1803, and pupde of the blowfly Protocalliphora azurea Fall 1817 Dermanyssus gallinoides is a fast-moving mite in which both adults and some nymphal stages are haemdtophagous (Cheng 1978), adults of the blowfly $P$ azurea are not ectoparasitic, but female flies search for birds" nests to lay eggs which develop into larvae that take blood meals from their nestling hosts (Bennett and Whitworth 1991) Cerataphyllus gallinae is a common ectoparasitic flea of hole-nesting birds, in which only the adults are hematophagous (George 1959, Cheng 1978)

\section{Variation in weather conditions}

There were significant differences $(p<001$. Tukey's a posteriori tests from oneway ANOVAs of meteorological data) among the three study years in weather conditıons, mostly due to June 1992 being significantly colder and rainy than the same period in 1991 and 1993 ( $\mathrm{F}_{1 \mathrm{~g}}$ 1) June 1992 was exceptional in that in 19 days mean temperatures did not exceed $10^{\circ} \mathrm{C}(0$ days in 1991 and 1993) and. unlike in 1991 and 1993, periods with rainfall (16 d in 1992 vs 5 and 10 in 1991 and 1993 . respectively) were also significantly colder (Spearman rank correlation $r_{s 30}=-040, p=003$ ) By contrast. rainfall and temperature in 1991 and 1993 were closer to long-term weather conditions in this montane supramediterranean area (Izco 1984), where rainfall in June is usually limited to short-duration evening storms

\section{Abundance and prevalence of nest ectoparasites}

The abundance of the three ectoparasites varied significantly across the three years, with the lowest rates of infestation in 1992 (Fig 1. mites $\chi_{2}^{2}=782, p<001$, blowfly larvae $\chi_{2}^{2}=9.13, p=001$, fleas $\chi_{2}^{2}=1151$, $p<0001)$ There were no significant relationships between the abundances or prevalences of the three ectoparasites and the hatching date of the nests they were infesting, except for the number of blowfly larvae in $1991\left(\mathrm{r}_{\mathrm{s} 68}=037, \mathrm{p}=0003\right.$, in all other rank correlations $p>010$ ) We searched for patterns in mite and blowfly larvae abundance and flea prevalence, yearly effects, and possible interactions between different parasite species using log-linear analysis The four-way interaction among mites, blowflies. fleas and years was not significant $(G=159.2 \mathrm{~d} f, p=045)$ A hierarchcal model fitted to the variation of infestations across years retained an interaction term among the abundance scores of mites and blowfly larvae across years $(\mathrm{G}=638,2 \mathrm{df}, \mathrm{p}=004)$. so that there existed an apparent effect of repulsion between both parasites, $1 \mathrm{e}$ few nests $(<10 \%)$ had high abundance scores of both mites and blowfles The only other term retaned by the model, after controlling for the variation among years and abundances of the other nest ectoparasites, was the variation of flea prevalence across years $(G=$ $836,2 \mathrm{~d} \mathrm{f}, \mathrm{p}=0015$ ) Overall, the fit of the log-linear model containing these two terms was adequate (goodness-of-fit. $\mathrm{G}=1373,9 \mathrm{~d} \mathrm{f}, \mathrm{p}=013$ )

When abundances and prevalences of ectoparasites were compared with ranfall and average temperatures in the three study years, a clear pattern emerges ( $\mathrm{F}_{1 \mathrm{~g}}$ 1) These differences were parallel to between-year differences in temperatures and rainfall $\left(F_{1 g} 1\right)$, although the small number of data points precludes statistical testing The three nest ectoparasites were less prevalent in the coldest and wettest year (1992), although fleas fared comparatively well that year, in contrast to mites and blowfles (Fig 1)

\section{Rainfall, temperatures and nestling growth and survival}

Variation in mean withın-brood fledgling mass and tarsus length can be compared to weather conditions and parasite abundances in Fig 1 Mass of young was greater, on average, in the warmer year (1991) than in 1992 and $1993\left(F_{2203}=1503, p<00001\right)$ In addition, there were differences in mean tarsus length between 
years $\left(F_{2203}=502, p<0001\right)$ A posteriorı tests revealed this was due to reduced tarsus growth in 1993 , although no differences were found in the rest of pairwise compansons The frequency of nests with nestling mortality was higher in 1992 and 1993 than in 1991 $\left(\chi_{2}^{2}=1019, p=0006\right.$. Fig 1)

A
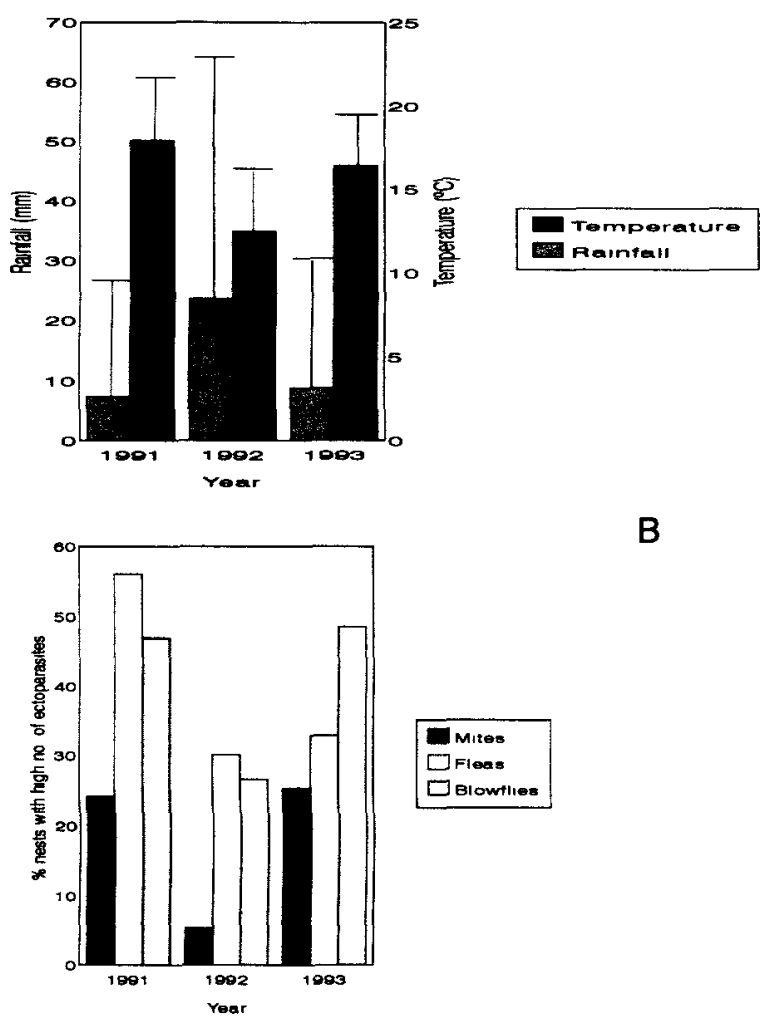

B

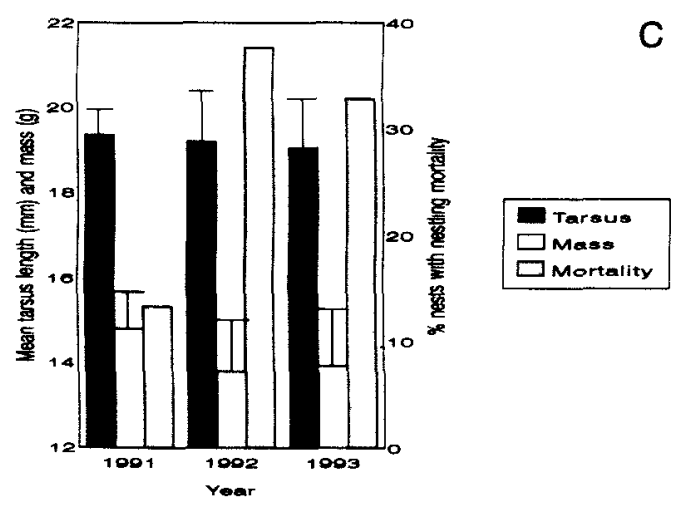

F1g 1 Yearly vanation in dverage (SD) rainfall (mm) and temperatures $\left({ }^{\circ} \mathrm{C}\right)(\mathrm{A})$, ectoparasite abundance scores low vs high, prevalences (percentage of infested nests) are used for fleas, (see text) (B), and average (SD) growth medsurements of nestling hosts and percentage of nests with nestling mortality (C)

\section{Parasites, nestling growth and survival}

Before analyzing the relationshıps between parasites and measurements of nestling growth we statistically controlled for other factors which are known to influence nestling development, namely breeding date, brood size, and parental size and condition (see Pott1 and Merıno 1994, Merıno and Pott1 1995) Table 1 summarizes the information on the effects the nest parasites had on the growth and mortality of nestling pied flycatchers in the three study years As expected, the effects of nest ectoparasites were, when significant, detrimental for nestling growth and survival untıl fledgling. reducing average nestling mass and tarsus length and decreasing survival in infested nests However, there was little consistency across years as to the identity of the ectoparasites that were detrimental (Table 1) Mites affected nestling growth in two out of three years fleas decreased nestling growth and increased mortality in one year and the only effect of blowfly larvae was on nesthing mortality in another. different year (Merıno and Pott1 1995)

\section{Discussion}

The changing weather conditions across years may be an important factor affecting the reproductive success of ectoparasites and hence, their hosts This was shown in this study by 1) the marked temporal variation of infestation rates by ectoparasites, 2) the apparent tight relationship of parasite abundance and prevalence with variable weather conditions, and 3) the differing effects of the three nest ectoparasite species on the survival and average size and mass of pied flycatcher broods Irrespective of parasite effects, weather effects on nestlings may be related to difficulties on the part of parents to obtain sufficient food for adequate nestling feeding in predominantly aerial-foraging avian species (e g Bryant 1975, Shields and Crook 1987, Johnson and Albrecht 1993) Thus, all else being equal, we could expect the effects of nest ectoparasites to be more detrimental in these circumstances However, the parasites themselves are also badly affected, as climate may be one of the main factors keeping in check insect ectoparasite populations, especially in those species which do not live permanently on their hosts (Marshall 1981) For instance, temperature has been shown to be a determinant influence on the growth, development and activity of some ectoparasites (Marshall 1981, Maurer and Baumgartner 1992) Thus, different weather conditions may account for the large differences among years in prevalences of ectoparasite species whose life cycles are largely decoupled from their temporary hosts, and must also have a bearing on their differing effects on hosts (e $g$ compare fleas and blowfly larvae prevalences with the constancy of feather louse prevalences (Pottı and Merino 1995)) 
The between-year variation in blowfly pupae prevalence and abundance was similar to the variation of temperature and rainfall This fact may be simply explained by paying attention to the life cycle and mode of infestation of this ectoparasite In spring, gravid blowfly females look for an adequate host nest to lay eggs (Bennett and Whitworth 1991) It should pay to blowfly females to arrive to host's nests at the first hours posthatching, because developmental time of their parasitic, blood-suckling larvae is similar to the tume elapsed from hatching to fledgling in their nestling passerine hosts (Bennett and Whitworth 1992) Rany and cold weather reduces the activity of flies and hence their prospects of breeding success (Bennett and Whitworth 1991, Rogers et al 1991) In 1992, and less markedly in 1993, blowfines could suffer from low temperatures and rany weather In 1991 blowflies were responsible for the high mortality of flycatcher nestlings, contrary to the other two years, possibly as a consequence of the higher numbers of this parasite in 1991

Fleas presumably suffered too from bad weather in 1992. as reflected by their lower prevalence that yedr However, the activity of fleas in bad weather may be not so much impaired as that of blowflies because fleas are remarkably adapted to cold temperatures (Marshall 1981), and their mode of transmission differs from that of blowflies in that they may be transported to their hosts" nests by attaching themselves to adult birds inspecting potential breeding and /or roosting holes that are flea-infested from previous years (George 1959 , Humphress 1968. Harper et al 1992, see also Richner et dl 1993. Merila and Allander 1995) In addition, fleas appear to be relatively favored by humidity (George 1959. Marshall 1981. Harper et al 1992) Although we did not quantify flea numbers, the latter fact may account for the effects of this ectoparasite on nestlings in 1992, along with the bad condition of nestlings that year Despite their low prevalence $(30 \%)$, the effects of fleas could be more severe in 1992 possibly as a consequence of adult fleas parasitizing nestlings in the first days of life, when bad weather did not allow for an adequate feeding of nestlings by flycatcher parents In years when food is presumably more abundant (1 e 1991) parental effort may help to compensate the negative effect that fleas may cause on nestling survival It is interesting to note that fleas, contrary to mites or blowflies, may have their detrimental effects on the first days of nestling life because adult fleas are parasites that need blood meals for forming eggs, while flea larvae do not feed on nestlings On the contrary both mites and blowfly larvae develop at the expense of host nestlings (Burtt et al 1991, Bennett and Whitworth 1991, Johnson and Albrecht 1993) attaining their higher resource demands when the nestlings are nearly fully grown
Mites produced detrimental effects on nestling growth in 1991 and 1993 Mite populations were apparently affected by the bad weather in 1992 However, at the end of the 1992 season, all nests were infested by mites and their numbers were as high as in 1991 This fact, as well as the lack of effects on nestling development in 1992, were likely caused by a delay in the development of mite populations Conditions for the development of mite populations were only favorable at the end of the pied flycatchers breeding period, when both temperature and humidity were high (see Burtt et al 1991. Maurer and Baumgartner 1992) So, in 1992 mites attained abundances as high as in the other two years, but only when weather conditions improved, and by then the effect they could cause on nestling growth was minimal Overall, Dermanyssus gallinordes mites were strikıng in their ability to actually infect most (Merıno and Pott 1995) pred flycatcher nests all seasons and under highly variable climate conditions The high population numbers which mites can attain ( $\approx 25000$ in some nests. Merıno and Pottı unpubl ) may enable $D$ gallinoides populations to colonize new hosts nests each year Their mode of colonization of nests in our ared remains unknown Cheng (1978) has reported on the possibility that mites may be transported to the nest by adult birds just as fleas do viz by attaching to birds inspecting suitable nest-sites However, we have not observed this mite species during inspections of birds recently arrived from spring migration Also, as nest boxes were not fumigated the possibility remains that some mites overwintered in the boxes and infested pied flycatcher nests the following spring However. prevalences of mites in recently erected, new clean nest boxes dre as high as in old nestboxes (Merino and Pottı unpubl). which runs against the latter argument We think it likely that some nest boxes may be infested through one or a feu gravid individuals transported by the adults among nest materials

Differences in prevalence and abundance of nest ectopardsites between years may explain some of the differing. apparently inconsistent effects caused on hosts Among the parasite species here considered, the results of our work across five years (see dlso Merino and Pott 1995) indicate that mites are rather consistent in their detrimental effects on the growth of nestling pied flycatchers, while fleas and blowflies have more unpredictable effects Furthermore, the detrimental effects of mites, as in other nest ectoparasites, may be more marked in years when hosts suffer from lack of food (de Lope et al 1993, Møller 1994a) or for birds breeding in poor territories (Merino and Pottı 1995) However. as ectoparasite populations suffer environmental effects as well. only those ectoparasites whose life cycle is in some way more "buffered" against some type of environmental stress, namely weather conditions, have the potential to cause detrimental effects on their hosts irrespective of weather conditions Also, 
different environmental conditions durıng the winter could kill off a varidble fraction of ectoparasite populations. thus affecting their abundances previous to the colonization of hosts" nests in the spring

In conclusion, climate conditions have determınant influences on both hosts and their nest ectoparasites, with subsequent highly vanable impacts on host fitness We must be cautious in makıng generalizations on host-parasite interactions obtained from only one or a few seasons if weather conditions are not controlled In addition to this already complex scenario, the possibility of interactions between different parasites (e g competition for host's resources) and their subsequent impact on host biology should also be considered, as not always these interactions will be in detriment of host fitness (Merino and Pottı 1995) Also, a simultaneous integration of host-parasite systems from both the parasites and host's perspectives is needed, as the detrimental effect of parasites might also be interpreted as being caused by reduced parental effort due to a lowered reproductive value of the offspring in presence of parasıtısm (Forbes 1993, Møller in press) Exper1mental studies manipulating parasite identities and intensities of infestations, and quantıfying parental effort in relation to parasitism and variable environmental conditions are needed to address alternative explanations on the effects of parasitism, and to see whether it is always the offspring who pays its costs (Johnson and Albrecht 1993. Møller in press)

Acknouledgements - We thank J Merila for constructıve comments on a first draft L M Carrascal and J P Veiga also provided helpful advice The study was funded by the Spanish DGICYT (project PB91-0084-C03-03)

\section{References}

Bennett, G F and Whitworth. T L 1991 Studies on the life history of some species of Protocalliphora (Diptera CalIıphoridae) - Can J Zool 69 2048-2058

- and Whitworth, T L 1992 Host, nest, and ecological relationshiops of speciesof Protocalliphora (Diptera Calliphoridae) - Can J Zool 70 51-61

Bryant, D M 1975 Breeding biology of house martins Deltchon urbica in relation to aerial insect abundance - Ib1s $117 \quad 180-216$

Burtt. E H Jr, Chow, W and Babbitt, G A 1991 Occurrence and demography of mites of tree swallow, house wren. and eastern bluebird nests - In Loye. J E and Zuk, M (eds), Bird-parasite interactions Ecology, evolution and behaviour Oxford Univ Press. Oxford, pp 104-122

Carrascal, L M. Pottl, J and Sanchez-Aguado, F J 1987 Spatio-temporal organization of the bird communities in two Mediterranean montane forests - Holarct Ecol 10 $185-192$

Cheng. T C 1978 Parasitologia general - AC, Madrid

Elkıns, N 1988 Weather and bird behaviour - T \& AD Poyser, Calton

Forbes, M R L 1993 Parasitism and host reproductive effort - Oikos $67 \quad 440-450$

George, R S 1959 Fleas from nests of the pued flycatcher and other species in the forest of Dean - Brit Birds 6 132-136
Harper, G H , Marchant, A and Boddington, D G 1992 The ecology of the hen flea Ceratophyllus gallinae and the moorhen fled Dasipsyllus gallmulae in nestboxes - J Anim Ecol 61 317-327

Humphries, D A 1968 The host-finding behaviour of the hen fled. Ceratophvllus gallinae (Schrank)(Siphonaptera) - Parasitology $58 \quad 403-414$

Izco, J 1984 Madrid verde - Ministerio Agricultura/Comunidad de Madrid Madnd

Jarvinen, A and Vatsanen, R A 1984 Reproduction of pied flycatchers (Fic edula hypoleuca) in good and bad breeding seasons in a northern marginal area - Auk $101 \quad 439-450$

Johnson, L S and Albrecht, D J 1993 Effects of hematophagous ectoparasites on nestling house wrens, Troglodites aedon who pays the cost of parasitism? Oikos $66 \quad 255-262$

Lehman, T 1993 Ectoparasites Direct impact on host fitness - Parasitol Today 9 8-13

Lope, de, F Gonzalez, G, Perez, J J and Møller, A P 1993 Increased detrimental effects of ectoparasites on their bird hosts durng adverse environmental conditions - Oecologia $95 \quad 234-240$

Loye, J E and Zuk, M 1991 Bird-parasite interactions Ecology, evolution and behaviour - Oxford Univ Press

Marshall, A G 1981 The ecology of ectoparasitic insects Academic Press, London

Maurer, V and Baumgartner, J 1992 Temperature influence on hife table statistics of the chicken mite Dermanissus gallinae (Acarı Dermanyssidae) - Exp Appl Acarology $15 \quad 27-40$

Merila, J and Allander K 1995 Do great tuts (Parus major) prefer ectoparasite-free roost sites ? - Ethology 99 53-60

Merino, S and Pottı, J 1995 Mites and blowflies decrease growth and survival in nestling pled flycatchers - Oıkos 73 $95-103$

Møller, A P 1990 Effects of parasitism by the haematophagous mite Ornithonissus bursa on reproduction in the barn swallow (Hirundo rustica) - Ecology 71 2345-2357

- 1994a Parasites as an environmental component of reproduction in birds as exemplified by the swallow Hirundo rustica - Ardea 82 161-172

- 1994b Sexual selection and the barn swallow - Oxford Univ Press, Oxford

- in press Parasitism and the evolution of host life history In Clayton, $\mathrm{D} H$ and Moore, $J$ (eds) Coevolutionary biology of birds and parasites Oxford Univ Press, Oxford

- Allander, K and Dufva, R 1990 Fitness effects of parasites on passerıne birds a review - In Blondel, $J$. Gosler, A, Lebreton, J -D and McCleery, R (eds), Population biology of passerine birds An integrated approach Springer. Berlın, pp 269-280

Munger, J C and Holmes, J C 1988 Benefits of parasitic infection a test using a ground squirrel-trypanosome system - Can J Zool 66 222-227

Potti, J and Merino, S 1994 Heritability estımates and maternal effects on tarsus length in pred flycatchers, Ficedula hypoleuca - Oecologia 100 331-338

- and Merino, S 1995 Louse loads of pied flycatchers Effects of host' sex, age, condition and relatedness - J Avian Biol 26 in press

- Sanchez-Aguado, F J, Blanco, D and Montalvo, S 1987 Breeding data for a population of pied flycatchers (Ficedula hypoleuca) in central Spain - Ardeola 34 105110

Poulın, R 1991 Group living and infestation by ectoparasites in passerines - Condor 93 418-423

Price, P 1980 Evolutionary biology of parasites - Princeton Univ Press, Princeton

Richner, K, Oppliger, A and Christe, P 1993 Effect of an ectoparasite on reproduction in great tits - J Anim Ecol $62703-710$

Rogers, C A , Robertson, R J and Stutchbury, B J 1991 Patterns and effects of parasitısm by Protocalliphora sialia 
on tree swallow nestlings - In Loye, J E and Zuk, $M$ (eds), Bird-parasite interactions Ecology, evolution and behaviour Oxford Univ Press, Oxford, pp 123139

Sdsvar1, L and Hegyi, Z 1993 The effects of parental age and weather on breeding performance of colonial and solitary tree sparrow (Passer montanus (L )) - Acta Oecologica 14 $477-487$

Shields, W M and Crook, J R 1987 Barn swallow coloniality A net cost for group breeding in the Adirondacks? Ecology $68 \quad 1373-1386$

Sokal, R R and Rohlf, F J 1981 Biometry 2nd ed Freeman, San Francisco

\section{Appendix}

Results of analyses of variance and covariance of mean nestling tarsus and mass and nestling mortality in relation to abundances of nest ectoparasites in the three study years (Table 1) Differences were tested while controlling for layıng date and parental measurements as covariates by means of ANCOVAs when those variables had significant influences on nestling growth. non parametric Kruskal-Wallıs analyses of variance were used for testing effects on number of dead nestlings MS mean squares

\section{Mites:}

1991

Nestling tarsus Layıng date $\mathrm{MS}=504 . \mathrm{F}=5187$, $\mathrm{p}<0001$, Male tarsus $\mathrm{MS}=063, \mathrm{~F}=653, \mathrm{p}=001$, Female tarsus $M S=256, F=2635, p<0001$, Mite dbundance $\mathrm{MS}=040, F=412, \mathrm{p}<005$, Nestling mass Mite abundance $\mathrm{MS}=567, \mathrm{~F}=965, \mathrm{p}=0003$ Number of dead nestlings $\mathrm{H}=058, \mathrm{p}=044$ 1992

Nestling tarsus Mite abundance $\mathrm{MS}=017, \mathrm{~F}=065$. $p=043$. Nestling mass Mite abundance $M S=032$, $F=025, p=063$ Number of dead nestlings $H=015$, $\mathrm{p}=070$

\section{3}

Nesthing tarsus Layıng date $M S=319 . F=1792$. $p<0001$, Male tarsus $M S=113, F=632, p=002$, Mite abundance $\mathrm{MS}=015, \quad \mathrm{~F}=087, \quad \mathrm{p}=037$, Nestlıng mass Layıng date $\mathrm{MS}=689, \mathrm{~F}=514, \mathrm{p}=$ 003 , Female mass $M S=853, F=637, p=001$, Mite abundance $M S=761, F=568, p=002$ Number of dead nestlings $\mathrm{H}=0.40, \mathrm{p}=053$

\section{Blowflies:}

1991

Nestling tarsus Layıng date $M S=400, F=3888$, $p<0001$, Male tarsus $M S=070, F=682, p=001$, Female tarsus $\mathrm{MS}=305 . \quad F=2969, \quad \mathrm{p}<0001$, Blowfly abundance $\mathrm{MS}=006, F=054, \mathrm{p}=047$, Nestling mass Laying date $\mathrm{MS}=341, \mathrm{~F}=534, \mathrm{p}=$ 003 , Blowfly abundance $\mathrm{MS}=053, \mathrm{~F}=0$ 83, $\mathrm{p}=$ 038 Number of dead nestlings $\mathrm{H}=800, \mathrm{p}=0005$

\section{2}

Nestling tarsus Blowfly abundance $\mathrm{MS}=043, \mathrm{~F}=$ 146, $p=023$ Nestling mass Blowfly abundance $\mathrm{MS}=149, \quad \mathrm{~F}=114, \quad \mathrm{p}=029 \quad$ Number of dead nestlings $\mathrm{H}=143 . \mathrm{p}=023$

1993

Nestling tarsus Laying date $\mathrm{MS}=321, \mathrm{~F}=1777$, $\mathrm{p}<0001$, Male tarsus $\mathrm{MS}=105, \mathrm{~F}=583, \mathrm{p}=002$, Blowfly abundance $\mathrm{MS}=033, \mathrm{~F}=180, \mathrm{p}=018$, Nestling mass Laying date $\mathrm{MS}=751, \mathrm{~F}=511, \mathrm{p}=$ 003 , Female mass $\mathrm{MS}=773, \mathrm{~F}=526, \mathrm{p}=003$. Blowfly abundance $\mathrm{MS}=032, \mathrm{~F}=022, \mathrm{p}=065$ Number of dead nestlings $\mathrm{H}=000, \mathrm{p}=097$

\section{Fleas:}

1991

Nestling tarsus Laying date $\mathrm{MS}=426, \mathrm{~F}=3991$. $\mathrm{p}<0001$, Male tarsus $\mathrm{MS}=053, \mathrm{~F}=497, \mathrm{p}=003$. Female tarsus $\mathrm{MS}=322, \mathrm{~F}=3023, \mathrm{p}<0001$, Flea abundance $\mathrm{MS}=007, \mathrm{~F}=069, \mathrm{p}=042$, Nestling mass Laying date $M S=719, F=1131, p=0001$, Flea abundance $\mathrm{MS}=132 . \mathrm{F}=207, \mathrm{p}=016$ Number of dead nestlings $\mathrm{H}=030, \mathrm{p}=058$ 1992

Nestling tarsus Flea abundance $\mathrm{MS}=178, \mathrm{~F}=642$, $\mathrm{p}=001$, Nestling mass Flea abundance $\mathrm{MS}=311$, $F=237 . p=013$ Number of dead nestlings $H=666$, $\mathrm{p}=001$

1993

Nestling tarsus Laying date $\mathrm{MS}=387, \mathrm{~F}=2639$, $\mathrm{p}<0001$, Male tarsus $\mathrm{MS}=080, \mathrm{~F}=544, \mathrm{p}=002$, Flea abundance $M S=036 . \quad F=242, \quad p=013$, Nestling mass Layıng date $\mathrm{MS}=729, \mathrm{~F}=557, \mathrm{p}=$ 002 . Female mass $M S=559, F=428, p=004$, Flea abundance $\mathrm{MS}=130, \mathrm{~F}=100, \mathrm{p}=033$ Number of dead nestlıngs $H=215, p=014$ 
This document is a scanned copy of a printed document. No warranty is given about the accuracy of the copy. Users should refer to the original published version of the material. 